\title{
EFETIVIDADE DA INOCULAÇÃO COM RIZÓBIO E FUNGOS MICORRIIZICOS ARBUSCULARES EM MUDAS DE SABIÁ SUBMETIDAS A DIFERENTES NÍVEIS DE FÓSFORO'
}

\author{
HÉLIO ALMEIDA BURITY², MARIA DO CARMO CATANHO PEREIRA DE LYRA ${ }^{3}$, EIDY SIMÕES DE SOUZA ${ }^{4}$ \\ ADÁLIA CAVALCANTI DO ESPÍRITO SANTO MERGULHÃO ${ }^{5}$ e MARIA LUIZA RIBEIRO BASTOS DA SILVA ${ }^{5}$
}

RESUMO - Visando otimizar a produção de mudas de sabiá (Mimosa caesalpiniifolia Benth), foi conduzido um experimento para avaliar a efetividade da dupla inoculação com fungos micorrízicos arbusculares (FMA) e rizóbio. Os tratamentos, arrumados em esquema fatorial consistiram de presença e ausência de Rhizobium sp. e de FMA (Glomus etunicatum, Acaulospora morrowae e A. longula), e de três níveis de $\mathrm{P}\left(0,20\right.$ e $40 \mathrm{~kg} / \mathrm{ha}$ de $\mathrm{P}_{2} \mathrm{O}_{5}$, na forma de superfosfato triplo). A aplicação de $\mathrm{P}$ na ausência e na presença dos fungos não favoreceu o desenvolvimento das plantas. As mudas com a dupla inoculação apresentaram valores significativos no crescimento, área foliar, altura das plantas, atividade da enzima nitrogenase, porcentagem de colonização radicular e outros parâmetros analisados, independentemente do nível de P usado. A nodulação do sabiá foi favorecida pela micorrização, uma vez que as mudas inoculadas apenas com Rhizobium apresentaram nodulação significativamente menor. Houve aumento da colonização micorrízica e diminuição da esporulação na presença de Rhizobium.

Termos para indexação: nodulação, colonização micorrízica, fungo vesículo-arbuscular, Rhizobium, Glomus etunicatum, Acaulospora morrowae, Acaulospora longula.

\section{EFFECTIVENESS OF INOCULATION WITH ARBUSCULAR MYCORRHIZAL FUNGI AND RHIZOBIUM SP. ON MIMOSA CAESALPINIIFOLIA SEEDLINGS,} UNDER DIFFERENT PHOSPHORUS LEVELS

\begin{abstract}
In order to optimize Mimosa caesalpiniifolia Benth seedlings production, an experiment was carried out to evaluate the inoculation with both arbuscular mycorrhizal fungi (AMF) and Rhizobium. Treatments, arranged in a factorial scheme, consisted of presence or absence of Rhizobium, and of AMF (a mixture of Glomus etunicatum, Acaulospora morrowae and A. longula), with three P levels (equivalent to 0,20 and $40 \mathrm{~kg} /$ ha of $\mathrm{P}_{2} \mathrm{O}_{5}$ ), applied as triple superphosphate. The $\mathrm{P}$ application, in the absence or in the presence of AMF inoculation, did not enhance plant development, while the seedlings which received the double inoculation presented significant values on growth, height, leaf area, nitrogenase activity and others analyzed parameters, regardless of the P level. Mimosa caesalpiniifolia nodulation was enhanced by the inoculation with AMF, since plants which received Rhizobium alone showed significantly lower nodulation values than the ones which received both inoculations. There was an increase of the mycorrhizal and a decrease of the esporulation in the presence of Rhizobium.

Index terms: nodulation, colonization mycorrhizae, vesicular-arbuscular micorhiza, Rhizobium, Glomus etunicatum, Acaulospora morrowae, Acaulospora longula.
\end{abstract}

\footnotetext{
${ }^{1}$ Aceito para publicação em 17 de maio de 1999.

${ }^{2}$ Eng. Agrôn., Ph.D., Laboratório de Biologia do Solo, IPA, Av. Gal. San Martin, 1.371 Bongi, Caixa Postal 1022, CEP 50671-000 Recife, PE. Bolsista do CNPq. E-mail: burity@ipa.br

${ }^{3}$ Eng. Agrôn., M.Sc., IPA, Recife, PE.

${ }^{4}$ Zoot., Dra., IPA, Recife, PE.

${ }^{5}$ Biól., M.Sc., IPA, Recife, PE.
}

\section{INTRODUÇÃO}

O uso de microrganismos com a finalidade de melhorar a disponibilidade de nutrientes às plantas é uma prática de grande importância e muito necessária para a agricultura. Entre os sistemas biológicos envolvendo planta e microrganismos, temos as simbioses leguminosas-rizóbio, de maior expressão econômica, e leguminosas-fungos micorrízicos 
arbusculares (FMA) que, a partir de estudos de Gerdermann (1975) também foi considerada importante para o processo de nodulação. Segundo Siqueira (1983), a dupla inoculação é capaz de reduzir os custos com fertilizantes nitrogenados e fosfatados, além de conferir às plantas maior capacidade de absorção de nutrientes, induzindo ao aumento na produtividade. O sabiá (Mimosa caesalpiniifolia Benth.) é uma das mais importantes leguminosas tropicais arbóreas, pela sua comprovada resistência à seca e rápido crescimento (Almeida et al., 1987) e por ser considerada indispensável em qualquer programa de reflorestamento na Região Nordeste, principalmente no Semi-Árido. Vasconcelos et al. (1984), estudando a ocorrência de Rhizobium e endomicorrizas em leguminosas arbóreas e arbustivas, observaram que $47,5 \%$ das plantas eram micorrizadas ou noduladas, enquanto $30 \%$ eram simultaneamente micorrizadas e noduladas, na qual o sabiá foi citado. Döbereiner (1984) relata que apenas $18 \%$ das espécies leguminosas arbóreas foram estudadas em relação a nodulação, entretanto, das 63 espécies florestais mais importantes que nodulavam, o sabiá estava presente. Silva (1995), estudando o efeito da inoculação com Bradyrhizobium e da calagem em sabiá, sob condições de solos ácidos, observou que as plantas inoculadas apresentaram melhor desenvolvimento e maior resistência à acidez quando comparadas com as plantas adubadas com $\mathrm{N}$ mineral, onde a cultura do sabiá não foi afetada pela acidez do solo.

$\mathrm{O}$ sucesso no estabelecimento da nodulação e fixação de $\mathrm{N}_{2}$ das leguminosas forrageiras depende de uma nutrição fosfatada adequada, e como as micorrizas aumentam a absorção de P, este elemento é de grande valor para a melhoria da fixação do $\mathrm{N}$ atmosférico, crescimento e efetiva nodulação da planta (Gibbson, 1976). Este trabalho teve como objetivo avaliar o efeito da dupla inoculação e diferentes níveis de $\mathrm{P}$ sobre o desenvolvimento de mudas de sabiá.

\section{MATERIAL E MÉTODOS}

O experimento foi realizado em casa de vegetação na Empresa Pernambucana de Pesquisa Agropecuária (IPA), com delineamento experimental em blocos ao acaso com arranjo fatorial $2 \times 2 \times 3$ (presença e ausência de fungos micorrízicos arbusculares (FMA) x presença e au- sência de rizóbio x 3 níveis de P), com quatro repetições. As sementes de sabiá foram imersas em álcool por dois minutos, escarificadas quimicamente com ácido sulfúrico por três minutos e esterilizadas com bicloreto de mercúrio a $0,5 \%$ por três minutos, e lavadas com água destilada. Posteriormente, foram mantidas em bandejas com uma camada de algodão (autoclavado por 20 minutos a $120^{\circ} \mathrm{C}$ ) embebida com água destilada, por dois dias, para germinar. O solo utilizado para o plantio foram os 20 primeiros centímetros de um Latossolo Vermelho-Amarelo, previamente esterilizado (autoclavado por 1 hora a $120^{\circ} \mathrm{C}$, em três dias consecutivos), com as seguintes características químicas: $\mathrm{pH}-6,7 ; \mathrm{Ca}^{2+}+\mathrm{Mg}^{2+}-16 \mathrm{mmol}_{\mathrm{c}} \mathrm{kg}^{-1}$ de solo; $\mathrm{K}-0,3$ mmol $_{\mathrm{c}} \mathrm{kg}^{-1}$ de solo; $\mathrm{P}-3,25 \mathrm{mg} \mathrm{kg}^{-1}$. O saco de plástico para as mudas tinha capacidade para $5 \mathrm{~kg}$ de solo. $\mathrm{O} P$ foi aplicado na forma de superfosfato triplo com níveis de 0,20 e $40 \mathrm{~kg} / \mathrm{ha}$ de $\mathrm{P}_{2} \mathrm{O}_{5}$. $\mathrm{O}$ inóculo de fungo micorrízico foi produzido em casa de vegetação, com substrato solo-vermiculita na proporção $3: 1$ (v:v), utilizando-se como planta multiplicadora o painço (Panicum millaceum) constituído de uma mistura das espécies Glomus etunicatum, Acaulospora morrowae e A. longula, com 70 esporos por grama de substrato, mais pedaços de raízes colonizadas colocados a $3 \mathrm{~cm}$ da superfície do saco. Quanto ao inóculo de rizóbio, foi constituído de uma população de células rizobianas de $10^{8} / \mathrm{mL}$ (SEMIA 6167). A colheita se deu aos 110 dias após o plantio, quando foram avaliados os seguintes parâmetros: altura das plantas; área foliar, através de medidor de área foliar marca Licor-Area meter, com medição não-destrutiva e resultados expressos em $\mathrm{cm}^{2}$; atividade da enzima nitrogenase, mediante análise de redução de acetileno, em um cromatógrafo de gás CG 27 equipado com detector de ionização de chama de hidrogênio e uma coluna Poropak $\mathrm{N}$, com $2 \mathrm{~cm}$ de comprimento e $1 / 8$ de diâmetro. A coluna foi operada isotermicamente a $40^{\circ} \mathrm{C}$, tendo o $\mathrm{N}$ como gás de arraste. A temperatura do vaporizador e do detetor foram de 140 e $160^{\circ} \mathrm{C}$, respectivamente. A matéria seca da parte aérea e raiz levadas à estufa, a $60-65^{\circ} \mathrm{C}$, com ventilação forçada, para secagem até o peso constante; matéria seca dos nódulos; contagem do número de esporos pelo método de Gerdemann \& Nicolson (1963) e porcentagem de colonização radicular foram estimadas pelo método de Phillips \& Hayman (1970). Os dados experimentais foram submetidos à análise de variância e ao teste de Tukey a 5\% de probabilidade.

\section{RESULTADOS E DISCUSSÃO}

Na Tabela 1, observa-se que houve interação significativa entre a inoculação com rizóbio e micorriza 
TABELA 1. Matéria seca dos nódulos, da parte aérea e raiz, altura da planta, área foliar, número de esporos, colonização radicular na presença e ausência de rizóbio e de fungos micorrízicos arbusculares (FMA) em diferentes níveis de $\mathbf{P}$ em sabiá (Mimosa caesalpiniifolia) ${ }^{1}$.

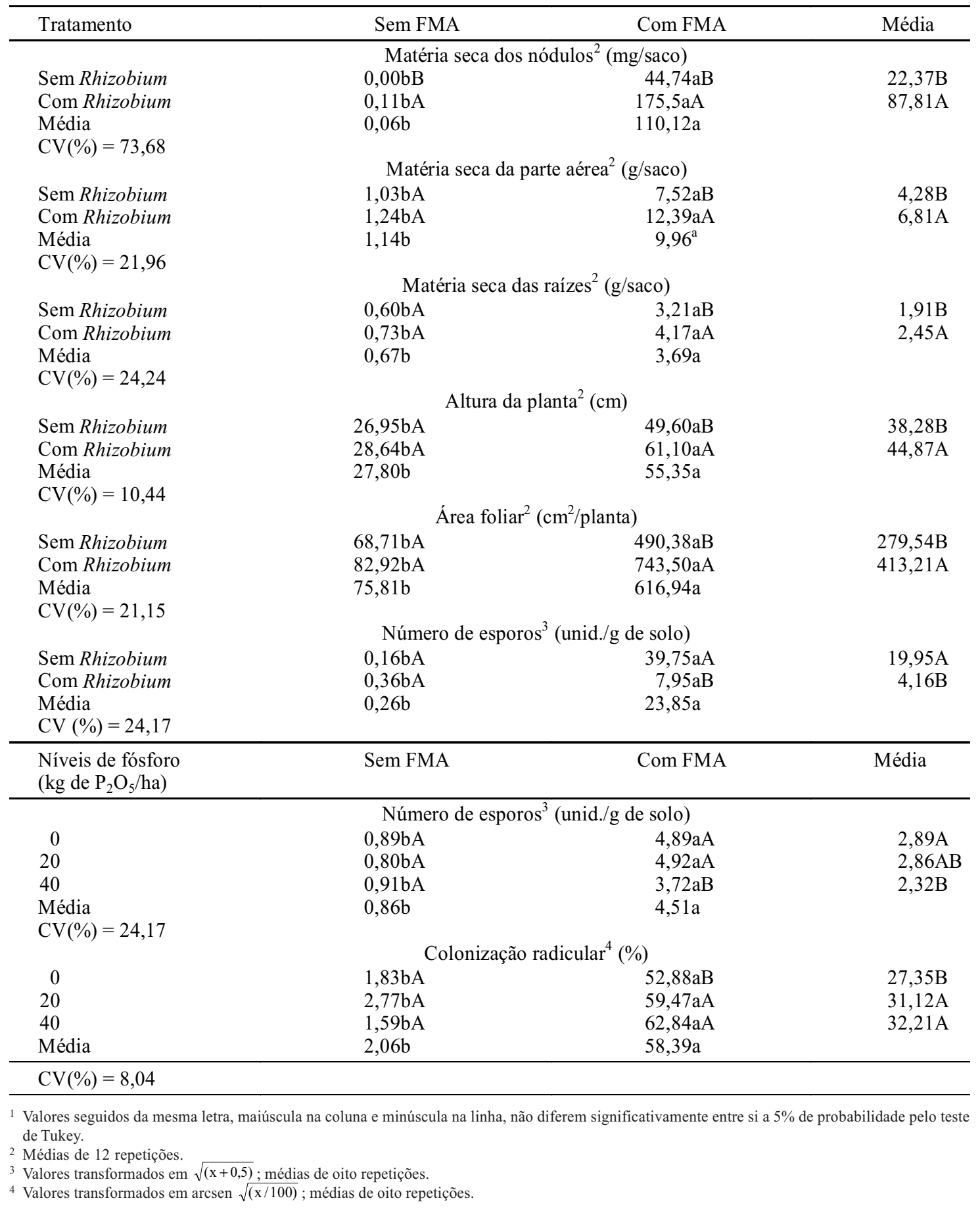


em relação à matéria seca dos nódulos (MSN), da parte aérea (MSPA) e raiz (MSR). Quando inoculou-se simultaneamente com rizóbio e micorriza, a MSN foi 392\% superior à inoculação isolada de FMA e mais de $159.000 \%$ superior à inoculação de rizóbio isolado, apesar de as médias isoladas de cada inóculo terem sido elevadas. A ocorrência de nodulação na ausência da inoculação rizobiana e na presença de fungos micorrízicos arbusculares talvez tenha sido causada por contaminação durante o processo de produção de inóculo com os fungos. Dados semelhantes foram observados por Bonetti (1989), quando estudou o efeito de micorrizas arbusculares na nodulação, crescimento e absorção de $\mathrm{P}$ e $\mathrm{N}$ em siratro. Segundo Pacovsky et al. (1986) e Silveira et al. (1995), as plantas quando micorrizadas geralmente apresentam um metabolismo mais elevado do que as não-micorrizadas, sendo capazes de fornecer maior quantidade de carboidratos e $\mathrm{P}$ ao rizóbio; conseqüentemente essas plantas apresentam uma nodulação significativamente maior. Os resultados do tratamento com dupla inoculação, em relação a MSPA e MSR, foram $64 \%$ e $30 \%$, respectivamente, superiores em relação às mudas micorrizadas e $900 \%$ e $471 \%$ superiores em relação às mudas inoculadas apenas com rizóbio. Tais resultados corroboram os de Almeida et al. (1991), quando estudaram o efeito de níveis de $\mathrm{P}$ de rocha e da inoculação de Rhizobium sp. e Glomus macrocarpum sobre o desenvolvimento de jurema-preta. Em experimentos realizados com mudas de sabiá e leucena, também constatou-se a influência da dupla inoculação no rendimento da MSPA, porém os valores alcançados não foram estatisticamente significativos (Almeida et al., 1987). Em estudo com Albizia sp., inoculada com Glomus etunicatum e Rhizobium na presença de adubação fosfatada e nitrogenada, Faria et al. (1995) observaram que houve crescimento das plantas e aumento na nodulação quando inoculadas com Glomus etunicatum e adubadas com $\mathrm{P}$.

Os melhores resultados de altura de planta (AP) e área foliar (AF) (Tabela 1) foram observados na interação rizóbio-micorriza, apresentando-se $127 \% \mathrm{e}$ $982 \%$, respectivamente, superiores aos tratamentos controle. Com relação ao número de esporos no solo (NES), os resultados foram contrários aos obtidos para os parâmetros citados anteriormente; o NES foi maior no tratamento inoculado apenas com micorriza. Esses resultados podem indicar que a tríplice interação leguminosa-rizóbio-micorriza pode inibir a esporulação do FMA, apesar de ter promovido aumentos significativos na nodulação, MSPA, MSR, AF e AP. Outro fato que pode ter ocorrido foi, provavelmente, a presença de certos nutrientes que tenham proporcionado ao FMA condição favorável para a sobrevivência na planta hospedeira e, com isto, inibiu a esporulação do fungo no solo, uma vez que o esporo é uma estrutura de sobrevivência da espécie. Como as micorrizas precisam de uma condição equilibrada entre fungo-planta e ambiente (condições edafoclimáticas), faz-se necessário estudo mais aprofundado para se chegar a conclusões mais precisas do fato observado.

Ao analisarem-se os dados em função dos níveis de $\mathrm{P}$ estudados, percebeu-se que os parâmetros NES e colonização radicular (CR) apresentaram interação significativa com os FMA (Tabela 1); o nível de $40 \mathrm{~kg} / \mathrm{ha}$ de $\mathrm{P}_{2} \mathrm{O}_{5}$ (ou 20 ppm de $\mathrm{P}$ ) apresentou inibição da micorrização, uma vez que, com FMA, o NES foi superior nos níveis de 0 e $20 \mathrm{~kg} / \mathrm{ha}$ de $\mathrm{P}_{2} \mathrm{O}_{5}$ (0 e $10 \mathrm{ppm}$ ). Tais dados podem ser justificados provavelmente pelo efeito da aplicação do $\mathrm{P}$, inibindo a esporulação. Paula et al. (1993) apresentaram resultados semelhantes ao estudarem a ocorrência de FMA e de bactérias diazotróficas na cultura da batata-doce. Quanto à colonização radicular de FMA, os valores foram crescentes com o aumento dos níveis de $\mathrm{P}$; os níveis 20 e 40 foram superiores ao nível 0 , mas não diferiram entre si. $\mathrm{A}$ ação do $\mathrm{P}$ parece ocorrer por meio de sua concentração na planta (Sanders et al., 1975), portanto é possível imaginar que a aplicação de $\mathrm{P}$ possa ter um efeito diferente em função da espécie estudada. Segundo Menge et al. (1978), o mecanismo que regula a relação entre a infecção das raízes por FMA não é ainda bem conhecido, mas deve estar associado ao nível crítico interno de $\mathrm{P}$ da planta hospedeira. Almeida et al. (1987) observaram que na leucena e no sabiá, embora a inoculação com Glomus macrocarpum tenha causado um rendimento de freqüência e intensidade de infecção micorrízica, este não foi significativo em relação aos tratamentos 
não-inoculados em relação aos inoculados, cuja infecção foi determinada pelos endófitos nativos.

$\mathrm{O}$ nível de $\mathrm{P}$ aplicado não apresentou interação positiva com a altura da planta em função da inoculação com e sem rizóbio (Fig. 1). Os resultados relativos à atividade da nitrogenase (ARA) (Fig. 2) apresentaram uma interação significativa quando são comparados os tratamentos com dupla inoculação e sem rizóbio. Apesar de não ter havido diferença significativa entre as médias dos níveis, ao se analisar separadamente cada nível, nota-se que no nível 0, o ARA foi bem maior na dupla inoculação, com $312,81 \mu$ moles de $\mathrm{C}_{2} \mathrm{H}_{2} / \mathrm{h}$, com uma eficiência de $592 \%$, quando comparado com os tratamentos inoculados apenas com o rizóbio. Esses incrementos foram de $465 \%$ e $628 \%$ em relação aos níveis 20 e 40 , respectivamente. Segundo Smith et al. (1979) e Mosse (1981), a eficiência micorrízica no processo de fixação de $\mathrm{N}$ atmosférico foi observada em outras leguminosas, e o rendimento na fixação de $\mathrm{N}_{2}$ em rizóbio em mudas de sabiá pode ter sido favorecido pela micorrização que satisfaz a demanda de $\mathrm{P}$ nesse processo. Em solos com deficiência de $\mathrm{N}$ e $\mathrm{P}$, a relação entre FMA e o rizóbio é de grande importância; a fixação biológica do N, cuja eficiência depende de um balanço nutricional adequado na planta hospedeira, especialmente do nível de $\mathrm{P}$, pode depender também do status micorrízico da planta (Diederichs, 1990). De acordo com Sieverding (1992), a fixação de $\mathrm{N}$ requer bastante energia e estímulo ao crescimento, e maior absorção de $\mathrm{P}$ por fungos micorrízicos arbusculares, podendo aumentar a superfície de área foliar das leguminosas, que neste caso podem suplementar fotossintetatos suficientes para o simbionte e suprir a demanda de energia.

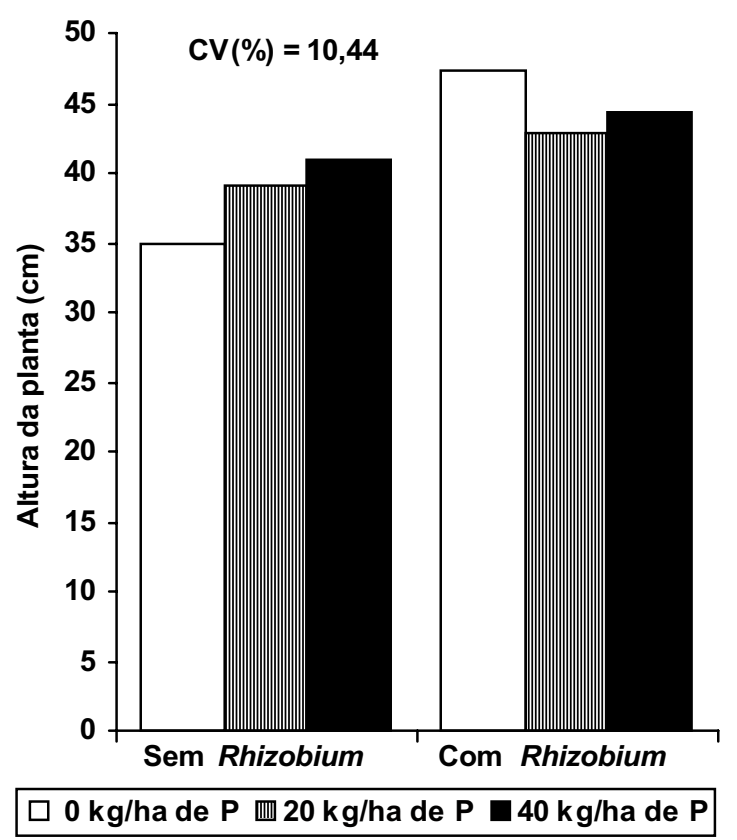

FIG. 1. Altura da planta na presença e ausência de Rhizobium em três diferentes níveis de $P$, em sabiá (Mimosa caesalpiniifolia). Média de 12 repetições.

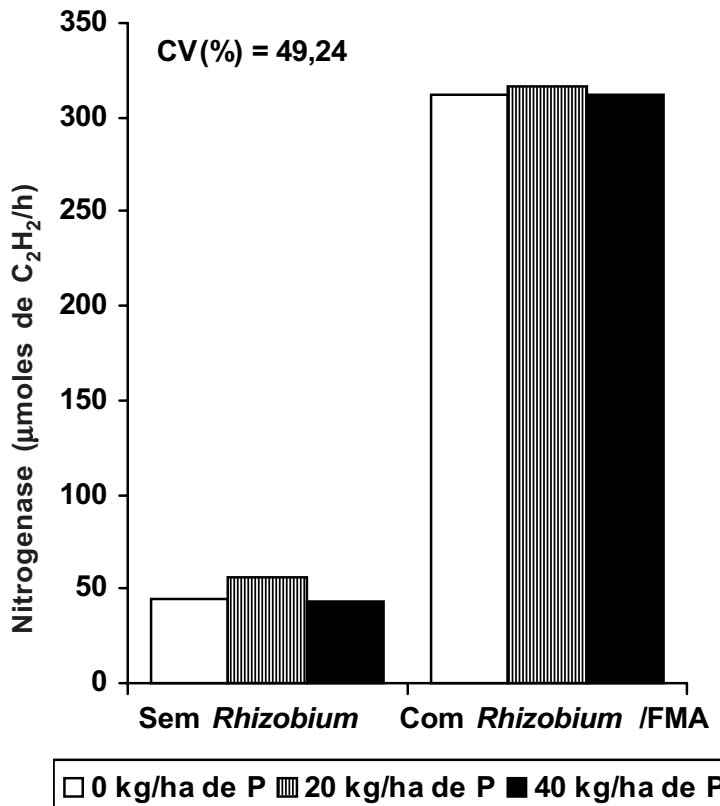

FIG. 2. Atividade da nitrogenase pelo método de redução de acetileno na presença da dupla inoculação e ausência de Rhizobium em três diferentes níveis de $\mathbf{P}$ em sabiá (Mimosa caesalpiniifolia). Média de 12 repetições. 


\section{CONCLUSÕES}

1. A dupla inoculação (rizóbio/micorriza) apresenta maior eficiência na nodulação, área foliar, colonização radicular e atividade da nitrogenase em relação à inoculação com rizóbio, em mudas de sabiá.

2. A presença do rizóbio aumenta a colonização micorrízica e diminui a esporulação.

3. Os níveis de $\mathrm{P}$ integram com número de esporos no solo, colonização radicular e atividade da nitrogenase; entretanto não diferem entre si quanto à melhor dosagem a ser aplicada na cultura do sabiá.

\section{REFERÊNCIAS}

ALMEIDA, R.T. de; FREIRE, V.F.; VASCONCELOS, I. Efeitos da interação Glomus macrocarpum, Rhizobium sp. e níveis crescentes de fosfatos de rocha sobre o desenvolvimento de mudas de sabiá (Mimosa caesalpiniaefolia) e de leucena (Leucena leucocephala Lam. de Witt). Ciência Agronômica, Fortaleza, v.18, n.1, p.131-136, 1987.

ALMEIDA, R.T. de; VASCONCELOS, L.; FREIRE, V.F. Efeito de níveis de fosfatos de rocha e da inoculação de Rhizobium sp. e Glomus macrocarpum Tul. sobre o desenvolvimento da jurema preta, Mimosa acutistipula Benth. Ciência Agronômica, Fortaleza, v.22, n.1/2, p.1-5, 1991.

BONETTI, R. Efeito de micorrizas vesiculares-arbusculares na nodulação, crescimento e absorção do fósforo e nitrogênio em siratro. Revista Brasileira de Ciência do Solo, Campinas, v.2, n.2, p.189-192, 1989.

DIEDERICHS, C. Improved growth of Cajanus cajan (L). Millsp. in an unsterile soil by three mycorrhizal fungi. Plant and Soil, Dordrecht, v.123, p.261-266, 1990

DÖBEREINER, J. Nodulação e fixação de nitrogênio em leguminosas florestais. Pesquisa Agropecuária Brasileira, Brasília, v.19, s/n, p.83-90, jun. 1984. Edição Especial.

FARIA, M.P.; SIQUEIRA, J.O.; VALEE, F.R.; CURI, N. Crescimento de leguminosas arbóreas em resposta a fósforo, nitrogênio, fungo micorrízico e rizóbio. I. Albizzia lebbeck (L.) Benth. Revista Árvore, Viçosa, v.19, n.3, p.293-307, 1995.
GERDEMANN, J.N. Vesicular-arbuscular micorrhiza. In. TORREY, J.G.; CLARKSON, D.T. (Eds.). The development and function of roots. New York : Academic, 1975. p.573-579.

GERDEMANN, J.N.; NICOLSON, T.H. Spores of mycorrhizal endogenaus species extracted from soil by wet sieving and decanting. British Mycological Society Transactions, Cambridge, Grã-Bretanha, v.46, n.2, p.235-244, 1963.

GIBBSON, A.H. Limitation to dinitrogen fixation in legumes. In: INTERNATIONAL SYMPOSIUM OF NITROGEN FIXATION, 1976, Washington. Proceedings. Washington : University Press, 1976. p.400-428.

MENGE, J.A.; STEIRLE, D.; BAGYARAJ, D.J.; JONHSON, E.L.V.; LEONARD, R.T. Phosphorus concentrations in plants responsable for inhibition of mycorrhizal infections. New Phytologist, Cambridge, Grã-Bretanha, v.80, p.75-80, 1978.

MOSSE, B. Vesicular-arbuscular mycorrhiza research for tropical agriculture. Hawaii : University of Hawaii-Institute for Tropical Agriculture and Human Resources, 1981. 82p. (ITAHR. Research Bulletin, 194).

PACOVSKY, R.S.; PAUL, E.A.; BETHLENTALVAY, G.J. Response of mycorrhizal and P-fertilized soybean to nodulation by Bradyrhizobium or ammonium nitrate. Crop Science, Madison, v.26, n.1, p.145-150, 1986.

PAULA, M.A.; SIQUEIRA, J.O.; DOBEREINER, J. Ocorrência de fungos micorrízicos vesiculo-arbusculares e de bactérias diazotróficas na cultura da batata-doce. Revista Brasileira de Ciência do Solo, Campinas, v.17, n.3, p.319-419, 1993.

PHILLIPS, J.M.; HAYMAN, D.S. Improved procedures for clearing roots and staining parasitic and vesicular-arbuscular mycorrhizal fungi for rapid assessment of infection. British Mycological Society Transactions, Cambridge, Grã-Bretanha, v.55, p.158-161, 1970.

SANDERS, F.E.; MOSSE, B.; TINKER, P.B. Endomycorrhizal inoculation in soil. New Zealand Journal of Agricultural Research, Wellington, v.23, p.219-223, 1975.

SIEVERDING, E. Vesicular-arbuscular mycorrhiza. [S.1.] : GTZ, 1992. 371p. 
SILVA, R.A. da. Efeito da inoculação com Bradyrhizobium e da calagem em sabiá (Mimosa caesalpiniaefolia) em dois solos ácidos do Estado de Pernambuco. Recife : UFRPE, 1995. 126p. Tese de Mestrado.

SILVEIRA, A.P.D.; FREITAS, S.S.; SILVA, L.R.C.; LOMBARDI, M.L.C.O.; CARDOSO, E.J.B.N. Interações de micorrizas arbusculares e rizobactérias promotoras do crescimento em plantas de feijão. Revista Brasileira de Ciência do Solo, Campinas, v.19, p.205-211, 1995.

SIQUEIRA, J.O. Nutritional and edhaphic factors affecting spores germination, germ tube and root colonization by vesicular-arbuscularmycorrhizal fungi. Gainsville : University of Florida, 1983. 159p. Ph.D. Thesis.

SMITH, S.E.; NICHOLAS, D.J.D.; SMITH, F.A. Effect of early mycorrhizal infection on nodulation and nitrogem fixation in Trifolium subterraneum L. Australian Journal of Plant Physiology, Melbourne, v.6, p.305-311, 1979.

VASCONCELOS, I.; ALMEIDA, R.T.; MENDES FILHO, P.F.; LADIM, C.M.V. Comportamento de 13 estirpes de Rhizobium sp. em simbiose com sabiá, Mimosa caesalpiniifolia Benth. Ciência Agronômica, Fortaleza, v.15, n.1/2, p.133-138, 1984. 